\title{
MENENTUKAN PREMI TAHUNAN UNTUK TIGA ORANG PADA ASURANSI JIWA HIDUP GABUNGAN (JOINT LIFE)
}

\author{
Tri Yana Bhuana ${ }^{\S 1}$, I Nyoman Widana ${ }^{2}$, Luh Putu Ida Harini ${ }^{3}$ \\ ${ }^{1}$ Jurusan Matematika, Fakultas MIPA - Universitas Udayana [Email: triyana.bhuana06@gmail.com] \\ ${ }^{2}$ Jurusan Matematika, Fakultas MIPA - Universitas Udayana [Email: nwidana@yahoo.com] \\ ${ }^{3}$ Jurusan Matematika, Fakultas MIPA - Universitas Udayana [Email: ballidah@gmail.com] \\ ${ }^{\S}$ Corresponding Author
}

\begin{abstract}
Life insurance products consist of a single life insurance and joint life insurance. Joint life is a state where the rule die life is a combination of two or more factors, such as the husband-wife, parentchild. The research is to obtain the formula of the annual premium of joint life insurance with the age of $x, y$, and $z$. By using formula and constants Helligmann-Pollard will be determined value of mortality tables, life annuity and single premium to get the formula annual premium joint life insurance for three persons. In addition, this study also aims to get the number of annual premium joint life insurance for a household of three consisting of a married couple and one son with the ages of 50, 45, dan 15 years old, with the interest rate of 5\% used. For the contract terms of one and two years, the annual premium of joint life for two persons respectively and greater than the joint life insurance of three persons. While for three to ten years contract, the annual premium of joint life insurance three person is bigger than the joint life insurance for two persons.
\end{abstract}

Keywords: Joint Life Insurance, Annual Premium Two Person, Annual Premium Three Person

\section{PENDAHULUAN}

Kejadian seperti kecelakaan, sakit, kerusakan atau kehilangan harta benda adalah sebuah kejadian yang tidak terduga yang dapat dialami oleh siapapun. Ini menyebabkan masyarakat harus lebih menyiapkan diri dalam mengatasi resiko kejadian yang akan dialami. Salah satu cara untuk mengurangi resiko yang tidak pasti adalah dengan mengikuti asuransi. Menurut Sembiring [5] asuransi adalah jaminan atau pertanggungan terhadap kejadian yang tidak pasti. Terdapat banyak jenis-jenis asuransi yaitu asuransi pendidikan, asuransi kesehatan, asuransi dana pensiun, asuransi jiwa dan lainlain.

Asuransi jiwa merupakan program asuransi yang memberikan proteksi terhadap resiko pada jiwa seseorang yang menjadi tertanggung. Manfaat proteksi jiwa ini adalah jaminan kepastian terhadap tertanggung dan keluarga dalam menghadapi berbagai resiko kehidupan.
Ketika dalam resiko, maka manfaat asuransi pasti akan tetap memberikan seluruh manfaat dana pendidikan, dana pensiun maupun santunan meninggal yang direncanakan tanpa harus melanjutkan pembayaran preminya terhadap perusahaan asuransi jiwa.

Perusahaan asuransi jiwa merupakan perusahaan yang memberikan jasa dalam penanggulangan resiko yang dikaitkan dengan hidup dan meninggalnya seseorang yang dipertanggungkan. Suatu perusahaan asuransi jiwa tidak menutup kemungkinan untuk menawarkan produk asuransi kepada peserta yang ingin melakukan asuransi jiwa secara bersama atau asuransi jiwa hidup gabungan (Joint Life). Joint Life adalah suatu keadaan dimana aturan mati hidupnya merupakan gabungan dari dua faktor atau lebih, misalnya suami-istri, orang tua-anak (Futami [3]).

Melihat hasil penelitian Matvejevs \& Matvejevs [4] dan menggunakan arti dari Joint 
Life yang dijelaskan oleh Futami [3], maka pada tulisan ini akan dikaji besarnya premi yang harus dibayarkan pada asuransi jiwa hidup gabungan untuk tiga orang, selain itu penelitian ini juga bermaksud melihat apakah asuransi Joint Life untuk tiga orang juga memiliki kesimpulan yang sama dengan asuransi Joint Life untuk dua orang yang telah dibahas pada jurnal (Matvejevs \& Matvejevs [4]).

Tujuan dari penelitian ini adalah mendapatkan rumusan premi dari asuransi jiwa joint life untuk tiga orang dan membandingkan nilai premi dari asuransi jiwa joint life untuk dua orang dengan tiga orang.

\section{METODE PENELITIAN}

Kontrak asuransi untuk dua orang yang terdiri dari pasangan suami-istri, apabila peserta berusia $x$ tahun dan $y$ tahun tetap hidup mencapai kontrak asuransi berakhir atau dengan kata lain peserta mencapai usia $x+n$ dan $y+n$, maka peserta mendapatkan uang pertanggungan sebesar $Q$. Apabila salah satu dari peserta meninggal dunia sebelum masa kontrak misalnya apabila $y$ meninggal dunia sebelum masa kontrak berakhir maka $x$ mulai tahun ke- $n$ selama seumur hidup setiap tahunnya mendapatkan uang pertanggungan (benefit) sebesar $R_{x}$, demikian juga sebaliknya apabila $x$ meninggal dunia maka $y$ akan mendapat uang pertanggungan (benefit) sebesar $R_{y}$. Apabila kematian dari pasangan juga terjadi ( $x$ dan $y$ meninggal) sebelum kontrak berakhir maka ahli waris akan mendapatkan uang pertanggungan sejumlah premi yang telah dibayarkan, pada akhir tahun kematiannya (Futami [2]).

Perbandingan antara peluang meninggalnya peserta $x$ tahun sebelum mencapai usia $x+1$ tahun dengan peluang peserta $x$ tahun tetap bertahan hidup selama 1 tahun dapat dirumuskan sebagai (Matvejevs \& Matvejevs [4]):

$\frac{q_{x}}{p_{x}}=A^{(x+B)^{c}}+D \times \exp \left\{-E \times(\ln x-\ln F)^{2}\right\}+G \times H^{x}$

dengan $A, B, C, D, E, F, G, H$ merupakan nilai kostanta, disajikan pada Tabel 2.1 dibawah ini
Tabel 2.1. Nilai Konstanta dari Formula Helligman-Pollard

\begin{tabular}{|l|l|l|}
\hline Konstan & Pria & Wanita \\
\hline A & 0.00194 & 0.00115 \\
\hline B & 0.05093 & 0.03310 \\
\hline C & 0.14249 & 0.12811 \\
\hline D & 0.00607 & 0.00029 \\
\hline E & 1.61992 & 23.44606 \\
\hline F & 57.83349 & 21.11713 \\
\hline G & 0.00005 & 0.00006 \\
\hline H & 1.10715 & 1.09116 \\
\hline
\end{tabular}

Sumber: Matvejevs \& Matvejevs [4].

Peluang orang berusia $x_{1}, x_{2}, \ldots, x_{m}, 1$ tahun kemudian akan tetap hidup dinotasikan dengan $p_{x_{1} x_{2} \ldots x_{m}}$ dan dirumuskan sebagai:

$$
{ }_{n} p_{x_{1} x_{2} \ldots x_{m}}={ }_{n} p_{x_{1}} \times{ }_{n} p_{x_{2}} \times \ldots \times{ }_{n} p_{x_{m}}
$$

Dan Peluang orang berusia $x_{1}, x_{2}, \ldots, x_{m}$ dalam jangka waktu $n$ tahun akan meninggal semua dinotasikan dengan ${ }_{n} q_{\overline{x_{1} x_{2} \ldots x_{m}}}$ dan dirumuskan sebagai (Futami [3]):

$$
{ }_{n} q_{\overline{x_{1} x_{2} \ldots x_{m}}}={ }_{n} q_{x_{1}} \times{ }_{n} q_{x_{2}} \times \ldots \times{ }_{n} q_{x_{m}}
$$

Anuitas hidup adalah suatu rangkaian pembayaran yang dilakukan apabila orang yang membayarnya masih hidup (Bowers [1]).

Anuitas yang pembayarannya dijanjikan akan dilakukan selang beberapa waktu kemudian disebut anuitas tunda (Futami [2]). Anuitas yang ditunda pembayarannya ada yang dilakukan di awal tahun dapat dirumuskan sebagai

$$
{ }_{n} \mid \ddot{a}_{x}=\sum_{t=n}^{\infty} v^{t}{ }_{t} p_{x}=\sum_{t=n}^{\infty} \frac{D_{x+t}}{D_{x}}=\frac{N_{x+n}}{D_{x}}
$$

Nilai sekarang anuitas awal dari anuitas hidup berjangka joint life untuk dua orang atau lebih tetap hidup dirumuskan sebagai (Futami [3]):

$$
\begin{aligned}
\ddot{a}_{x_{1} x_{2} \ldots x_{m}: \bar{n} \mid}= & 1+v \cdot p_{x_{1} x_{2} \ldots x_{m}}+v^{2} \cdot{ }_{2} p_{x_{1} x_{2} \ldots x_{m}}+ \\
& \ldots+v^{n-1}{ }_{n-1} p_{x_{1} x_{2} \ldots x_{m}}
\end{aligned}
$$


Besar premi ditentukan dengan prinsip ekivalensi dan mempunyai persamaan

$$
E(L)=0 .
$$

Dengan L menyatakan besarnya kerugian pihak penanggung yang didefinisikan sebagai variabel random dari nilai tunai benefit yang dibayarkan pihak penanggung.

Premi tunggal adalah pembayaran premi asuransi yang dilakukan pada waktu kontrak asuransi disetujui, selanjutnya tidak ada pembayaran lagi. Menurut Futami [2] premi tunggal pure endowment adalah pembayaran premi pada suatu kontrak asuransi jiwa yang dibayarkan pemegang polis, mulai dari saat kontrak dimulai sampai dengan jangka waktu tertentu.

Premi tunggal pure endowment joint life untuk peserta yang berusia $x$ tahun dan $y$ tahun, dengan jangka waktu tertanggung $n$ tahun dan besar uang pertanggungan adalah Rp. 1 dirumuskan sebagai:

$$
A_{x y:} \frac{1}{n \mid}=v^{n}{ }_{n} p_{x y} .
$$

Premi tunggal pure endowment joint life untuk peserta yang berusia $x, y$, dan $z$ tahun dirumuskan sebagai berikut (Futami [3]):

$$
A_{x y z: \frac{1}{n} \mid}=v^{n} \cdot{ }_{n} p_{x y z}
$$

Asuransi berjangka adalah suatu asuransi apabila pemegang polis mulai disetujuinya kontrak asuransi sampai dengan jangka waktu tertentu (meninggal) sebelum masa kontrak selesai maka akan dibayarkan uang pertanggungannya . Premi tunggal asuransi berjangka joint life dengan usia peserta $x$ tahun dan $y$ tahun dirumuskan sebagai

$$
A_{x y: \bar{n} \mid}^{1}=\sum_{t=1}^{n} v^{t}\left({ }_{t-1} p_{x y}-{ }_{t} p_{x y}\right)
$$

Premi tunggal asuransi berjangka joint life untuk usia $x, y$, dan $z$ tahun yang dirumuskan sebagai berikut (Futami [3]):

$$
A_{x y z: \bar{n}}^{1}=\sum_{t=1}^{n} v^{t}\left({ }_{t-1} p_{x y z}-{ }_{t} p_{x y z}\right)
$$

Usia tertanggung $x$ tahun, $y$ tahun, dan $z$ tahun meninggal pada tahun polis pertama besarnya uang pertanggungan dikalikan 1 , meninggal tahun polis kedua besarnya uang pertanggungan dikalikan 2, dan seterusnya. Setiap tahun apabila meninggal besarnya uang pertanggungan selalu bertambah 1. Asuransi yang demikian ini disebut juga asuransi berjangka menaik. Untuk masa pertanggungan selama $n$ tahun dan peserta $x$ dan $y$ tahun, uang pertanggungan dibayarkan pada akhir masa pertanggungan, single preminya dinotasikan dengan $(I A)_{x y: \bar{n} \mid}^{1}$ dan dirumuskan sebagai

$$
(I A)_{x y: \bar{n} \mid}^{1}=\sum_{t=1}^{n} t \cdot v^{t}\left({ }_{t} p_{x y}-{ }_{t+1} p_{x y}\right)
$$

Untuk peserta usia $x, y$, dan $z$ tahun dirumuskan sebagai (Futami [3]):

$$
(I A)_{x y z: \bar{n} \mid}^{1}=\sum_{t=1}^{n} t \cdot v^{t}\left({ }_{t-1} p_{x y z}-{ }_{t} p_{x y z}\right)
$$

Sehubungan dengan asuransi tersebut maka menurut Futami [3] nilai tunai dari pendapatan premi dan nilai tunai dari benefit yang dibayarkan oleh pihak penanggung dapat dirumuskan sebagai:

1. Nilai tunai dari pendapatan premi tahunan konstan pada joint life dapat dinyatakan sebagai

$$
P \cdot\left(1+v \cdot p_{x y}+v^{2} \cdot{ }_{2} p_{x y}+\ldots+v^{n-1} \cdot{ }_{n-1} p_{x y}\right)=P \cdot \ddot{a}_{x y \cdot \bar{n} \mid}
$$

2. Nilai tunai dari benefit yang dibayarkan oleh pihak penanggung dapat dinyatakan sebagai

$$
\begin{aligned}
& Q \cdot v^{n} \cdot{ }_{n} p_{x y}+R_{x} \sum_{m=0}^{n-1} \sum_{k=n}^{\infty} v^{k} \cdot{ }_{k} p_{x} \cdot{ }_{m} \mid q_{y} \\
& +R_{y} \sum_{k=0}^{n-1} \sum_{m=n}^{\infty} v^{m} \cdot{ }_{m} p_{y} \cdot{ }_{k} \mid q_{x}+P \cdot(I A)_{x y: \bar{n} \mid}^{1} \\
& =Q \cdot A_{x y: \bar{n} \mid}+R_{x} \cdot{ }_{n} \mid \ddot{a}_{x} \cdot{ }_{n} q_{y} \\
& \quad+R_{y} \cdot{ }_{n} \mid \ddot{a}_{y} \cdot{ }_{n} q_{x}+P \cdot(I A)_{x y: \bar{n} \mid}^{1}
\end{aligned}
$$

3. Dengan menggunakan prinsip ekivalensi, besar preminya adalah

$$
\begin{aligned}
P \cdot \ddot{a}_{x y: \bar{n} \mid}= & Q \cdot A_{x y: \bar{n} \mid}^{1}+R_{x} \cdot{ }_{n} \mid \ddot{a}_{x} \cdot{ }_{n} q_{y} \\
& +R_{y} \cdot{ }_{n} \mid \ddot{a}_{y} \cdot{ }_{n} q_{x}+P \cdot(I A)_{x y: \bar{n} \mid}^{1}
\end{aligned}
$$

Sehingga besarnya premi tahunan yang harus dibayarkan oleh peserta asuransi adalah 


$$
P=\frac{Q \cdot A_{x y: \bar{n} \mid}^{1}+R_{x} \cdot{ }_{n}\left|\ddot{a}_{x} \cdot{ }_{n} q_{y}+R_{y} \cdot{ }_{n}\right| \ddot{a}_{y} \cdot{ }_{n} q_{x}}{\ddot{a}_{x y: \bar{n} \mid}-(I A)_{x y \cdot \bar{n} \mid}^{1}}
$$

(Matvejevs \& Matvejevs [4]).

\section{HASIL DAN PENELITIAN}

Pada bab ini akan diuraikan hasil dan pembahasan dari masalah yang telah dijelaskan sebelumnya.

\section{Premi Tahunan Dua Orang}

Nilai premi tahunan dua orang pada asuransi joint life sudah dicari dengan menggunakan rumus yang sudah dijelaskan di atas yaitu

$$
x=50, y=45, R_{x}=R_{y}=Q=1 n=1-10 \text { tahun }
$$

Sehingga diperoleh $P=0,327517331$ untuk kontrak 10 tahun

\section{Formula Premi Tahunan Tiga Orang}

Kontrak asuransi melibatkan pasangan suami, istri, dan anak laki-lakinya dengan usia berturut-turut $x$. $y$, dan $z$ tahun. Pembayaran premi dilakukan $n$ tahun selama peserta masih hidup.

Rincian kontrak dari uang pertanggungan (benefit) adalah

a. Apabila peserta berusia $x$ tahun, $y$ tahun, dan $z$ tahun tetap hidup sampai kontrak asuransi berakhir maka peserta mendapatkan uang pertanggungan sebesar $Q$.

b. Apabila salah satu dari peserta meninggal dunia sebelum masa kontrak berakhir dan kedua peserta sisanya tetap hidup hingga akhir kontrak akan mendapatkan uang pertanggungan setiap tahunnya misalnya, apabila $x$ meninggal dunia sebelum masa kontrak berakhir maka pembayaran premi dihentikan dan apabila $z$ tetap hidup hingga masa kontrak berakhir maka $y$ dan $z$ mulai tahun ke- $n$ akan mendapatkan uang pertanggungan (benefit) sebesar $R_{y z}$ seumur hidup setiap tahunnya. Begitu pula $R_{x z}$ akan diberikan apabila $y$ meninggal dan $R_{x y}$ akan diberikan apabila $z$ meninggal sebelum akhir kontrak.

c. Apabila dua peserta meninggal dunia sebelum kontrak berakhir dan satu peserta sisanya tetap hidup setelah kontrak berakhir misalnya, apabila $x$ dan $y$ meninggal dunia sebelum masa kontrak berakhir maka pembayaran premi dihentikan dan apabila $z$ tetap hidup hingga kontrak berakhir maka $z$ mulai tahun ke- $n$ akan mendapatkan uang pertanggungan (benefit) sebesar $R_{z}$ seumur hidup setiap tahunnya. Begitu pula $R_{y}$ akan diberikan apabila $x$ dan $z$ meninggal dan $R_{x}$ akan diberikan apabila $y$ dan $z$ meninggal sebelum akhir kontrak.

d. Apabila ada peserta $x, y$, atau $z$ meninggal dunia sebelum kontrak berakhir maka ahli waris akan mendapatkan uang pertanggungan sejumlah premi yang telah dibayarkan, pada akhir tahun kematian.

Sehubungan dengan kontrak asuransi tersebut maka nilai tunai dari pendapatan premi dan nilai tunai dari benefit yang dibayarkan oleh pihak penanggung dapat dirumuskan sebagai

1. Nilai tunai dari pendapatan premi tahunan tiga orang pada joint life dapat dinyatakan sebagai

$$
\begin{aligned}
& P \cdot\left(1+v \cdot p_{x y z}+v^{2} \cdot{ }_{2} p_{x y z}+\ldots+v^{n-1} \cdot{ }_{n-1} p_{x y z}\right) \\
& =P \cdot \ddot{a}_{x y z: \bar{n} \mid}
\end{aligned}
$$

2. Nilai tunai dari pengembalian premi yang dibayarkan oleh pihak penanggung dinyatakan sebagai

$$
\begin{aligned}
& Q \cdot A_{x y z: \bar{n}}+R_{y z} \cdot{ }_{n}\left|\ddot{a}_{y z} \cdot{ }_{n} q_{x}+R_{x z} \cdot{ }_{n}\right| \ddot{a}_{x z} \cdot{ }_{n} q_{y} \\
& +R_{x y} \cdot{ }_{n}\left|\ddot{a}_{x y \cdot{ }_{n}} q_{z}+R_{z} \cdot{ }_{n}\right| \ddot{a}_{z} \cdot{ }_{n} q_{x y}+R_{x} \cdot{ }_{n} \mid \ddot{a}_{x} \cdot{ }_{n} q_{y z} \\
& +R_{y \cdot{ }_{n}} \mid \ddot{a}_{y} \cdot{ }_{n} q_{x z}+P \cdot(I A)_{x y z: \bar{n}}^{1}
\end{aligned}
$$

3. Dengan menggunakan prinsip ekivalensi, besar preminya adalah

$$
\begin{aligned}
& P \cdot \ddot{a}_{x y z: \bar{n} \mid}=Q \cdot A_{x y z: \bar{n} \mid}+R_{y z} \cdot{ }_{n} \mid \ddot{a}_{y z} \cdot{ }_{n} q_{x}+ \\
& R_{x z} \cdot{ }_{n}\left|\ddot{a}_{x z} \cdot{ }_{n} q_{y}+R_{x y} \cdot{ }_{n}\right| \ddot{a}_{x y} \cdot{ }_{n} q_{z}+
\end{aligned}
$$




$$
\begin{aligned}
& R_{z} \cdot{ }_{n}\left|\ddot{a}_{z} \cdot{ }_{n} q_{\overline{x y}}+R_{x} \cdot{ }_{n}\right| \ddot{a}_{x} \cdot{ }_{n} q_{\overline{y z}}+ \\
& R_{y} \cdot{ }_{n} \mid \ddot{a}_{y} \cdot{ }_{n} q_{\overline{x z}}+P \cdot(I A)_{x y z: \bar{n} \mid}^{1}
\end{aligned}
$$

Dengan demikian dapat ditentukan formula premi tahunan tiga orang yang harus dibayarkan peserta asuransi joint life, yaitu:

$$
\begin{aligned}
& P=\frac{1}{\ddot{a}_{x y: n \bar{n}}-(I A)_{x y z \cdot \bar{n} \mid}^{1}} \times \\
& \left(Q \cdot A_{x y z: \bar{n} \mid}+R_{y z} \cdot{ }_{n}\left|\ddot{a}_{y z}{ }_{n} q_{x}+R_{x z} \cdot{ }_{n}\right| \ddot{a}_{x z} \cdot{ }_{n} q_{y}\right. \\
& +R_{x y} \cdot{ }_{n}\left|\ddot{a}_{x y} \cdot{ }_{n} q_{z}+R_{z} \cdot{ }_{n}\right| \ddot{a}_{z} \cdot{ }_{n} q_{x y} \\
& \left.+R_{x} \cdot{ }_{n}\left|\ddot{a}_{x} \cdot{ }_{n} q_{\overline{y z}}+R_{y} \cdot{ }_{n}\right| \ddot{a}_{y} \cdot{ }_{n} q_{\overline{x z}}\right)
\end{aligned}
$$

Akan diberikan contoh kasus untuk memudahkan pehamaman rumusan asuransi jiwa joint life untuk tiga orang.

Contoh perhitungan (ilustrasi kasus)

1. Usia mulai asuransi

Usia mulai asuransi adalah usia yang ditetapkan sebagai mulainya peserta (suami,istri, dan anak laki-lakinya) mengikuti asuransi. Dalam kasus ini, usia suami $(x)$ adalah 50 tahun, usia istri $(y)$ adalah 45 tahun, dan usia anak laki-laki $(z)$ adalah 15 tahun.

2. Masa pertanggungan asuransi

Masa pertanggungan asuransi adalah lamanya peserta melakukan kontrak asuransi. Dalam kasus ini, ditetapkan masa pertanggungan asuransi $n=1-$ 10tahun.

3. Tingkat bunga

Besarnya tingkat bunga yang digunakan adalah konstan yaitu $i=5 \%$.

4. Santunan

Besarnya santunan setelah masa pertanggungan berakhir apabila ketiga peserta masih hidup, maka mereka akan diberikan uang sejumlah 1 rupiah $(Q=1$ rupiah) demikian juga apabila $(x)$ meninggal dan $(y),(z)$ tetap hidup diakhir kontrak, maka (y) dan (z) akan memperoleh 1 rupiah $\left(R_{y z}=1\right.$ rupiah) setiap tahunnya selama seumur hidup. Begitu pula ( $R_{x z}=1$ rupiah) akan diberikan apabila $y$ meninggal dan $\left(R_{x y}=1\right.$ rupiah $)$ akan diberikan apabila $z$ meninggal sebelum akhir kontrak demikian juga untuk $(x)$ dan $(y)$ meninggal dan $(z)$ tetap hidup diakhir kontrak, maka (z) akan mendapatkan 1 rupiah $\left(R_{z}=1\right.$ rupiah). Begitu pula $R_{y}$ akan diberikan apabila $x$ dan $z$ meninggal dan $R_{x}$ akan diberikan apabila $y$ dan $z$ meninggal sebelum akhir kontrak. Tetapi apabila ada $(x),(y)$, atau $(z)$ meninggal dunia sebelum kontrak berakhir, maka semua pembayaran premi yang telah dibayarkan akan dikembalikan.

Berdasarkan rumus premi tahunan untuk dua orang diperoleh premi tahunan kontrak tahun pertama sebesar 1,201491031 dan pada kontrak tahun ke-10 besarnya premi yang harus dibayar sebesar 0,327517331. Untuk premi tahunan tiga orang didapatkan besarnya premi yang harus dibayar dengan menggunakan rumus/formula yang telah dicari diatas. Besarnya premi tahunan kontrak tahun pertama untuk tiga orang sebesar 1,200632037 dan pada kontrak tahun ke-10 besarnya premi yang harus dibayar sebesar 0,339401372 .

Setelah mendapatkan hasil dari premi tahunan dua orang dan tiga orang maka dapat dibandingkan hasilnya. Dapat dilihat pada Tabel 3.1.

Tabel 3.1. Premi Tahunan untuk Dua dan Tiga

\begin{tabular}{|l|l|l|}
\hline $\begin{array}{l}\text { Kontrak } \\
n \text { Tahun }\end{array}$ & $\begin{array}{c}\text { Premi Tahunan } \\
\text { Asuransi Jiwa } \\
\text { Joint Life Dua } \\
\text { Orang }\end{array}$ & $\begin{array}{c}\text { Premi Tahunan } \\
\text { Asuransi Jiwa } \\
\text { Joint Life Tiga } \\
\text { Orang }\end{array}$ \\
\hline 1 & 1,201491031 & 1,200632037 \\
\hline 2 & 0,714018912 & 0,714000232 \\
\hline 3 & 0,551820648 & 0,55276117 \\
\hline 4 & 0,470958853 & 0,472987494 \\
\hline 5 & 0,422643744 & 0,425898742 \\
\hline 6 & 0,390608505 & 0,395238488 \\
\hline 7 & 0,367876905 & 0,374042439 \\
\hline 8 & 0,350954903 & 0,358830341 \\
\hline 9 & 0,337894202 & 0,347669764 \\
\hline 10 & 0,327517331 & 0,339401372 \\
\hline
\end{tabular}


Jika dinyatakan dalam grafik nilai dari premi tahunan asuransi jiwa hidup gabungan (joint life) untuk dua dan tiga orang dapat dilihat pada Gambar 1.

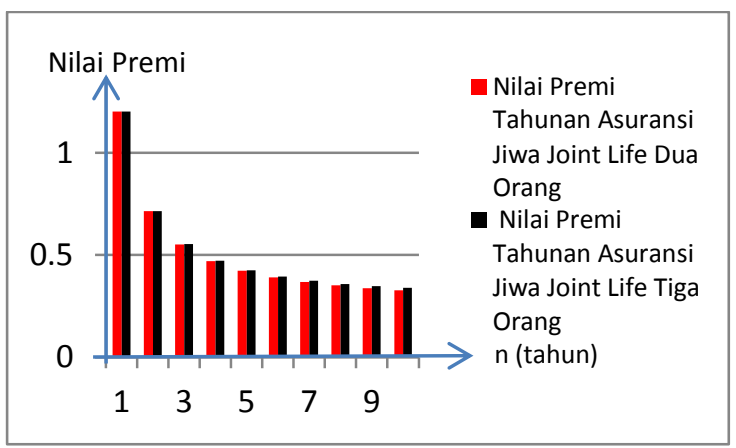

Gambar 1. Premi Tahunan untuk Dua dan Tiga Orang

Terlihat berdasarkan Tabel 3.1 bahwa dengan selisih 0,000858994 pada kontrak satu tahun dan selisih 0,00001868 pada kontrak dua tahun nilai premi tahunan untuk dua orang lebih besar daripada premi tahunan tiga orang. Sedangkan pada kontrak tiga hingga sepuluh tahun dengan selisih 0,000940522, $0,002028641, \quad 0,003254998, \quad 0,004629983$, $0,006165534, \quad 0,007875438, \quad 0,009775562$, 0,011884041 premi tahunan untuk tiga orang lebih besar nilainya daripada nilai premi tahunan untuk dua orang.

Dapat dijelaskan berdasarkan Gambar 1 terlihat bahwa nilai asuransi jiwa hidup gabungan (joint life) untuk dua dan tiga orang memiliki nilai premi yang menurun setiap tahunnya.

\section{KESIMPULAN DAN SARAN}

Berdasarkan hasil dan pembahasan yang dijelaskan maka kesimpulan yang didapat berupa rumusan premi tahunan asuransi jiwa hidup gabungan (joint life) untuk tiga orang sebagai berikut:

$$
\begin{aligned}
& P=\frac{1}{\ddot{a}_{x y z: \bar{n} \mid}-(I A)_{x y z: \bar{n} \mid}^{1}} \times \\
& \left(Q \cdot A_{x y z: \bar{n} \mid}+R_{y z} \cdot{ }_{n}\left|\ddot{a}_{y z} \cdot{ }_{n} q_{x}+R_{x z}{ }_{n}\right| \ddot{a}_{x z} \cdot{ }_{n} q_{y}\right. \\
& +R_{x y} \cdot{ }_{n}\left|\ddot{a}_{x y} \cdot{ }_{n} q_{z}+R_{z} \cdot{ }_{n}\right| \ddot{a}_{z} \cdot{ }_{n} q_{\overline{x y}} \\
& \left.+R_{x} \cdot{ }_{n}\left|\ddot{a}_{x} \cdot{ }_{n} q_{\overline{y z}}+R_{y} \cdot{ }_{n}\right| \ddot{a}_{y} \cdot{ }_{n} q_{\overline{x z}}\right)
\end{aligned}
$$

Melihat perbandingan besarnya nilai premi tahunan asuransi jiwa hidup gabungan (joint life) untuk dua orang dengan usia $x=$ 50 tahun dan $y=45$ tahun dan dengan menambahkan usia $z=15$ tahun akan mempengaruhi nilai tabel mortalitas, anuitas hidup, dan premi tunggal untuk premi tahunan asuransi jiwa hidup gabungan (joint life) tiga orang sehingga mendapatkan nilai premi tahunan asuransi jiwa hidup gabungan (joint life) untuk dua orang lebih besar saat kontrak asuransi satu dan dua tahun. Sedangkan pada saat kontrak tiga tahun hingga sepuluh tahun premi tahunan asuransi jiwa hidup gabungan (joint life) untuk tiga orang lebih besar dibandingkan asuransi jiwa hidup gabungan (joint life) untuk dua orang.

Saran yang penulis ingin sampaikan pada pengembangan penelitian selanjutnya adalah diharapkan dapat menggunakan joint life pada asuransi kesehatan.

\section{DAFTAR PUSTAKA}

[1] Bowers, N. et al., 1997. Actuarial Mathematics. Schaumburg: The Society of Actuaries.

[2] Futami, T., 1993. Matematika Asuransi Jiwa Bagian I. Tokyo: Oriental Life Insurance Cultural Development Center.

Jiwa Bagian II. Tokyo: Oriental Life Insurance Cultural Development Center.

[4] Matvejevs, A. \& Matvejevs, A., 2001. Insurance Models for Joint Life and Last Survivor Benefit. Informatica. 12(4), pp.547-558.

[5] Sembiring, R.K., 1986. Asuransi I. Jakarta: Universitas Terbuka, Depdikbud. 